\title{
Why a diaminopyrrolic tripodal receptor binds mannosides in acetonitrile but not in water?
}

\author{
Diogo Vila-Viçosa ${ }^{1}$, Oscar Francesconi ${ }^{2}$ and Miguel Machuqueiro ${ }^{* 1}$
}

\section{Full Research Paper}

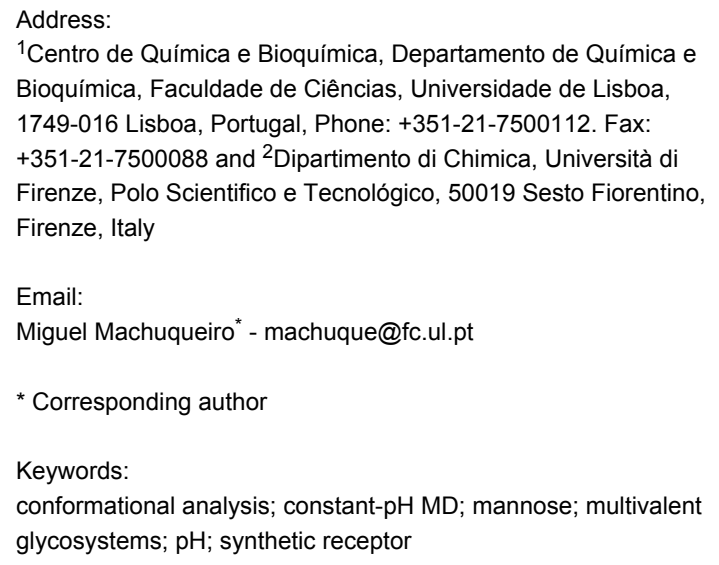

Beilstein J. Org. Chem. 2014, 10, 1513-1523. doi:10.3762/bjoc. 10.156

Received: 26 February 2014

Accepted: 28 May 2014

Published: 03 July 2014

This article is part of the Thematic Series "Multivalent glycosystems for nanoscience".

Guest Editor: A. Casnati

(C) 2014 Vila-Viçosa et al; licensee Beilstein-Institut.

License and terms: see end of document.

\begin{abstract}
Intermolecular interactions involving carbohydrates and their natural receptors play important roles in several biological processes. The development of synthetic receptors is very useful to study these recognition processes. Recently, it was synthetized a diaminopyrrolic tripodal receptor that is selective for mannosides, which are obtained from mannose, a sugar with significant relevance in living systems. However, this receptor is significantly more active in acetonitrile than in water. In this work, we performed several molecular dynamics and constant-pH molecular dynamics simulations in acetonitrile and water to evaluate the conformational space of the receptor and to understand the molecular detail of the receptor-mannoside interaction. The protonation states sampled by the receptor show that the positive charges are always as distant as possible in order to avoid large intramolecular repulsions. Moreover, the conformational space of the receptor is very similar in water above $\mathrm{pH} 4.0$ and in acetonitrile. From the simulations with the mannoside, we observe that the interactions are more specific in acetonitrile (mainly hydrogen bonds) than in water (mainly hydrophobic). Our results suggest that the readiness of the receptor to bind mannoside is not significantly affected in water (above pH 4.0). Probably, the hydrogen bond network that is formed in acetonitrile (which is weaker in water) is the main reason for the higher activity in this solvent. This work also presents a new implementation of the stochastic titration constant-pH molecular dynamics method to a synthetic receptor of sugars and attests its ability to describe the protonation/conformation coupling in these molecules.
\end{abstract}

\section{Introduction}

The recognition of specific carbohydrates is an important step in several biological processes [1]. To better understand these recognition processes, several synthetic receptors have been developed over the years [1-6]. Most of these were developed for glucose since it is one of the most common sugars in living systems [7] and the preferred monosaccharide for energy 
storage [8]. However, mannose is essential for various biological functions, such as molecular recognition, being one of the most abundant sugars in glycoconjugates $[9,10]$.

In 2011, Roelens' group [11-13] synthetized and tested a chiral diaminopyrrolic tripodal receptor that showed high binding affinities to mannosides (Figure 1). This particular receptor is significantly more active in acetonitrile $(\mathrm{ACN})$ than in water [14]. In fact, this receptor family [11-13] could only be tested in water at slightly acidic conditions, due to solubility reasons, and proved to be very inefficient [14]. Unraveling the molecular details of these host-guest interactions is crucial to understand their different performances when changing the solvent and to identify the molecular determinants behind the reported high affinities.

Simulation methods, namely the so-called constant-pH molecular dynamics (CpHMD) methods, have been used to understand the molecular detail of several phenomena in the last years [15-24]. Since MD simulations deal with $\mathrm{pH}$ in a limited way, simply by setting a fixed protonation state in the beginning of the simulation, the use of one of these methods is mandatory. The stochastic titration constant-pH MD method $[15,21]$ takes advantage from the complementarity between molecular mechanics/molecular dynamics (MM/MD) simulations, that correctly samples the conformational space of a system according to a classic potential energy function, and Poisson-Boltzmann/Monte Carlo methods, that can efficiently treat multiple protonation equilibria on rigid structures [25,26]. This way, it is possible to deal with $\mathrm{pH}$ as an external parameter that is fixed in our simulations since the protonation state of the titrable groups is allowed to periodically change during the simulation capturing the coupling between protonation and conformation. This method was already successfully applied to peptides and proteins in recent years [15,21,27-36].

The interaction of sugar molecules with receptors has been studied and shown that the recognition process involves many hydrogen bonds between the two molecules [1,37]. Aqvist et al, using MM/MD simulations, showed that the major contribution to the binding energy between both glucose and galactose to a proteic receptor, came from hydrogen bonds [38]. Moreover, Lerbret et al, suggested that hydrogen bonds are strongly related with the influence of sugar molecules in lysozyme structure $[39,40]$.

In this work, we performed an exhaustive conformational study of a chiral diaminopyrrolic tripodal receptor (Figure 1) in both water and acetonitrile. We used MM/MD simulations in the organic solvent and constant-pH MD to simulate the receptor in water at several $\mathrm{pH}$ values. Moreover, the interaction between the receptor and octyl $\alpha$-D-mannoside (the receptor binds strongly both $\alpha$ and $\beta$ anomers [12]) was also studied in these two solvents. These two approaches intend to address two working hypothesis: the receptor is active in acetonitrile but not in water due to the different conformational behavior in the two environments or due to specific interactions that are (un)favored when changing the solvent. This work also extends, for the first time, the use of the stochastic titration constant-pH MD method to artificial molecules, in particular to diaminopyrrolic receptors.

\section{Results and Discussion Titration curve of the receptor}

The titration curve of the receptor was obtained by averaging the occupancy of all titrable amine groups at each $\mathrm{pH}$ value

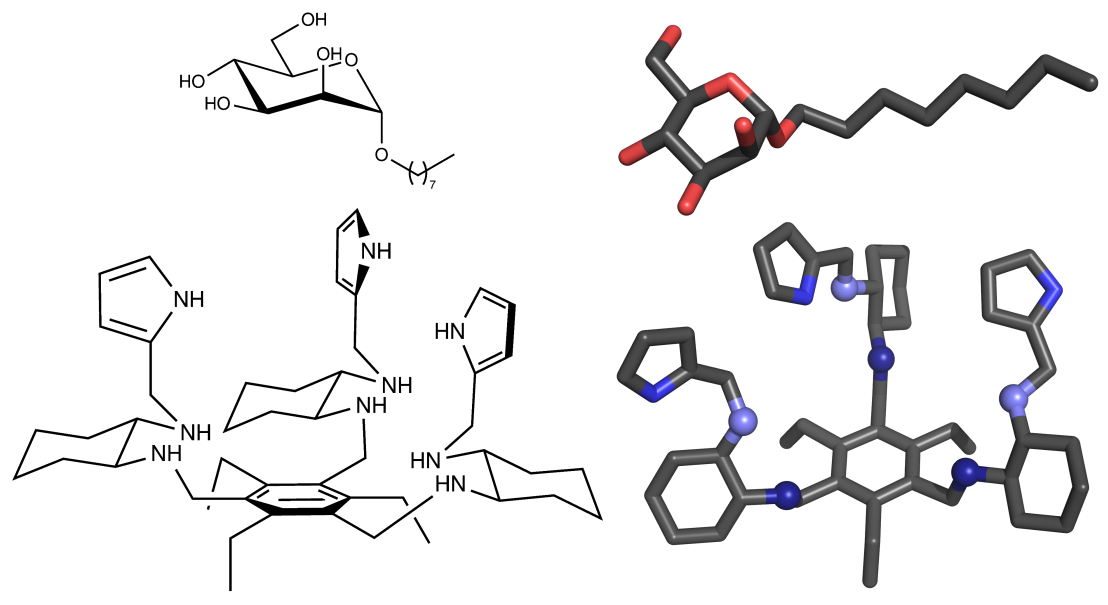

Figure 1: Octyl $\alpha$-D-mannoside (mannoside) and diaminopyrrolic tripodal receptor molecules. 2D and 3D representations are shown. In 3D, all hydrogen atoms were omitted for clarity, and titrable amino groups are shown in spheres with first generation in dark blue and second in light blue. 
over $270 \mathrm{~ns}$ (last $90 \mathrm{~ns}$ of each replicate). The total titration curve (Figure 2a) shows a clear plateau between $\mathrm{pH} 4.0$ and 7.0, approximately. In these range, the total protonation is $\sim 3$ meaning that half of the titrable groups are protonated and the total charge of the receptor is 3. At an extremely high (low) $\mathrm{pH}$ value the molecule is completely deprotonated (protonated) which means that the protonation range is completely sampled. From the total titration curve, we can also conclude that our receptor is only close to neutrality at $\mathrm{pH} 10.0$. From the individual titration curves of the first and second generation residues (Figure 1), we can determine which of these groups are being protonated at each $\mathrm{pH}$ value (Figure $2 \mathrm{~b}$ ). We observe that, in the plateau between $\mathrm{pH} 4.0$ and 7.0, the second generation has an average protonation of $75 \%$ and the first, $25 \%$. The higher charge in the second generation amine groups is expected since these groups are more exposed to the solvent, interacting less with each other, which means that they are easier to ionize. In the case of the first generation amino groups, they are much closer to each other, with limited conformational freedom, resulting in much lower $\mathrm{p} K_{\mathrm{a}}$ values.

The small number of titrable sites in the receptor allows us to analyze in detail the population of each possible microstate. In particular, from the populations of all simulated $\mathrm{pH}$ values, it is possible to draw a diagram to represent which states are more populated at each number of titrable protons present in the molecule (Figure 3). For example, when the molecule has one proton, it can be in one amino group of the first generation or in the second generation. However, if the molecule has two protons, they can be both in the first generation, both in the second generation, in different generations but in the same arm, or in different arms of the molecule (by arms we consider the diaminopyrrolic groups attached to the center phenyl group). From Figure 3, we observe that, in general, the position of protons (positive charges) is such that repulsion is minimized. For example, with two protons, the preferred state is the one with two second generation amino groups protonated which allows the two charges to be more distant to each other. Interestingly, there are many states that are almost not populated. In particular, with five protons, the state with three protons in the first generation is almost not populated since this state implies the presence of three positive charges in a very small space. With one proton, the preferred state is the one with the proton in the second generation which is more exposed to the solvent. However, since the global charge of the receptor is only one in this state, both microstates are significantly populated. With two and four protons, the observations are similar since in both cases the microstates with the second generation amino groups protonated are preferred and the ones with protons in different arms are also significantly populated. In these states, there are two microstates that are almost not populated due to the high
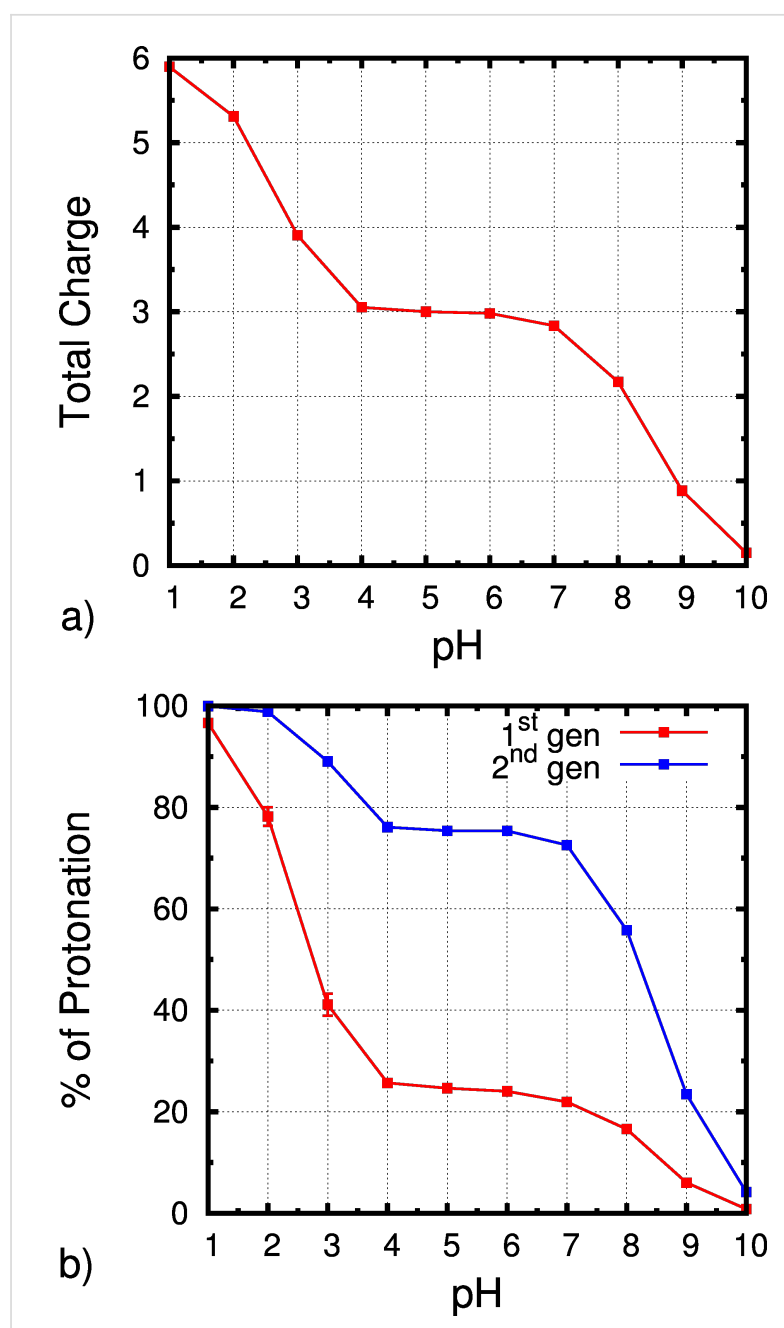

Figure 2: Full titration curve of the receptor (a) and the correspondent percentage of protonation in each generation (b).

repulsion when protonating two groups in the same arm or in the first generation. Finally, with three protons, only three (out of six) microstates are significantly populated and these are the ones that allow for smaller repulsion, as observed in the previous cases. This analysis was also performed for each $\mathrm{pH}$ value (see Supporting Information File 1) and the observations are completely analogous to the described above. As expected, geometrically constrained titrable sites show strong interactions due to electrostatic repulsion which results in shifted $\mathrm{p} K_{\mathrm{a}}$ values and in some forbidden (not sampled) protonation states. These results illustrate the usefulness of the constant-pH MD methodologies and expose the strong limitations of classic MM/MD simulations to deal with such systems.

\section{Conformational analysis of the receptor}

As expected, both in $\mathrm{ACN}$ and in water at all simulated $\mathrm{pH}$ values, the receptor shows a large conformational variability. The radius of gyration $\left(R_{\mathrm{g}}\right)$ indicates how "open" is the struc- 

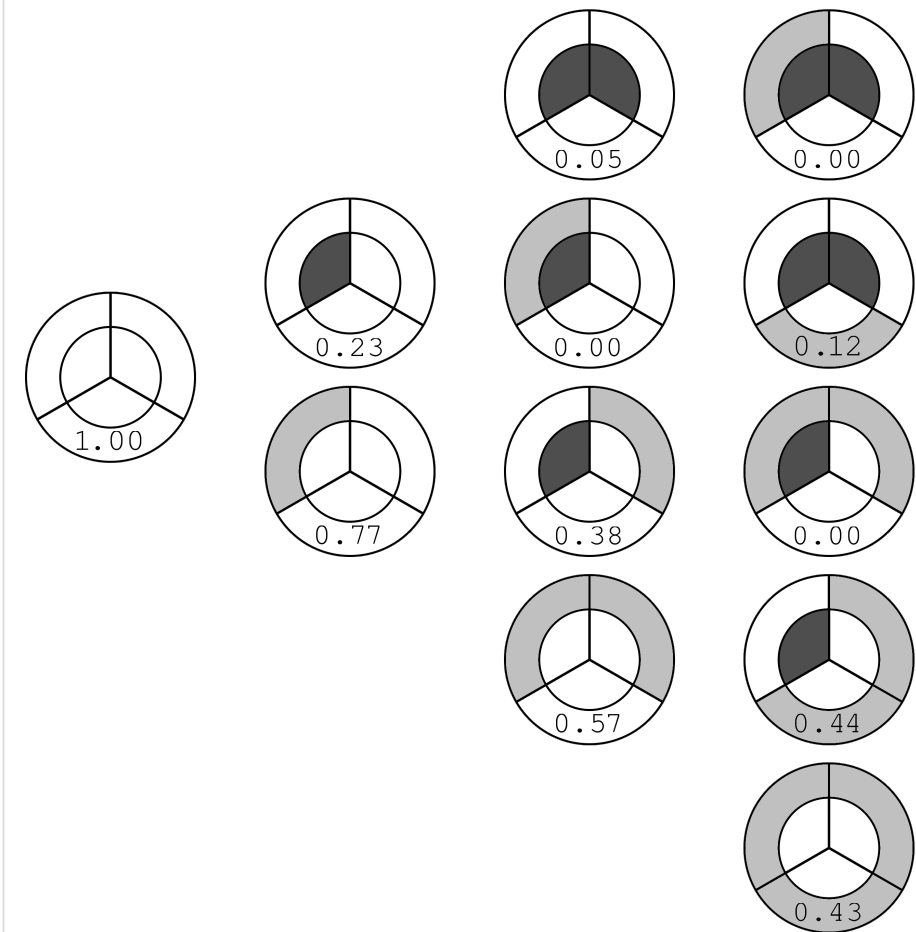
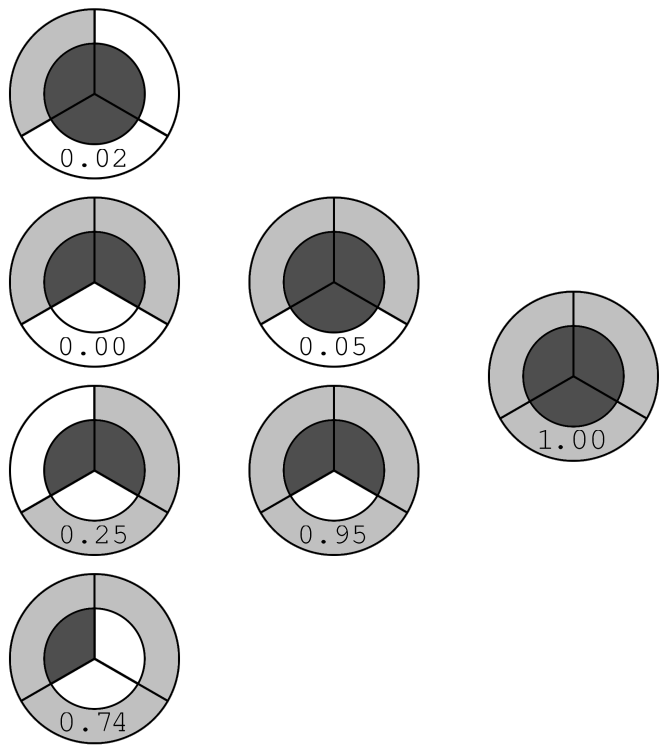

$n=4$

$n=5$

$n=6$

Figure 3: Diagram representing the population of all microstates at each number of titrable protons $(n)$ present in the molecule.

ture: a large $R_{\mathrm{g}}$ indicates that the receptor is in an extended conformation. Our results show that the receptor samples a large interval of $R_{\mathrm{g}}$ (Figure 4 and Supporting Information File 1). In fact, in most simulations, the molecule can sample "closed" conformations with $R_{\mathrm{g}}$ around $0.50 \mathrm{~nm}$ or more "open" with $R_{\mathrm{g}}$ larger than $0.65 \mathrm{~nm}$. However, at lower $\mathrm{pH}$ values, in particular at $\mathrm{pH} 1.0$, the distribution of $R_{\mathrm{g}}$ is much narrower and deviated to larger $R_{\mathrm{g}}$ values. As mentioned above, at $\mathrm{pH} 1.0$, the residues are almost completely charged and this generates significant repulsion between the arms which increases the $R_{\mathrm{g}}$. At $\mathrm{pH} 10.0$, the receptor is able to sample a very low $R_{\mathrm{g}}$ region (a shoulder in the histogram) that is almost inaccessible in the ACN simulations. These closed and packed conformations are favored when the receptor is neutral and is potentiated by its hydrophobicity, which does not happen in the organic solvent. Interestingly, above $\mathrm{pH} 4.0$, the distribution of $R_{\mathrm{g}}$ is very similar in all simulations and comparable with the simulations in ACN. This observation suggest that the conformational space, in terms of $R_{\mathrm{g}}$, is similar in water (above $\mathrm{pH} 4.0$ ) and in ACN. In other words, the receptor is able to accommodate up to 3 protons without any

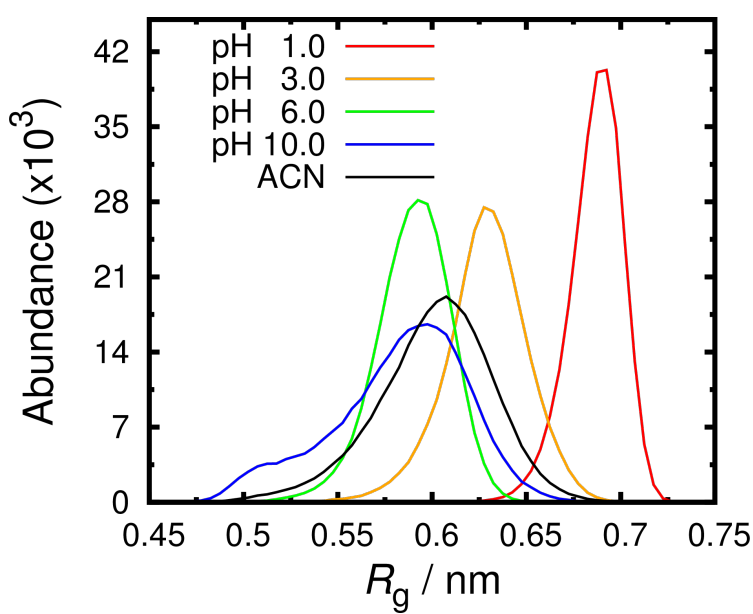

Figure 4: Radius of gyration $\left(R_{\mathrm{g}}\right)$ histograms for the receptor in water at $\mathrm{pH} 1.0,3.0,6.0,10.0$ and in $\mathrm{ACN}$. The $R_{\mathrm{g}}$ curves at the $\mathrm{pH}$ values not shown are well behaved and respect the observed trend. 
major influence in the preferred positions of its arms. This suggests that the reason hindering the receptor to bind sugars in water should not be its conformational readiness to establish specific intermolecular interactions.

To further characterize the conformational behavior of the receptor in water and $\mathrm{ACN}$, we combined two broadly used properties, namely $R_{\mathrm{g}}$ and RMSD, to obtain 2D-energy landscapes for each $\mathrm{pH}$ value and ACN (Figure 5 and Supporting Information File 1). In agreement with the $R_{\mathrm{g}}$ data, at low $\mathrm{pH}$ values, all sampled structures have both high $R_{\mathrm{g}}$ and RMSD. This means that, in more open conformations, the structure is also very different to the reference. Hence, in all these landscapes, we observe a correlation between RMSD and $R_{\mathrm{g}}$ properties. As the $\mathrm{pH}$ increases, more closed and lower RMSD structures are sampled. This is also in agreement with the $R_{\mathrm{g}}$ data which shows that the conformational space of the receptor at high $\mathrm{pH}$ values is similar to the one in $\mathrm{ACN}$.

Both $R_{\mathrm{g}}$ and energy landscapes data identify the position of the arms as a good descriptor of the receptor conformational space. Hence, we represented the positions of pyrrolic nitrogen atoms relative to the phenyl ring in 900 conformations (Figure 6 and Supporting Information File 1). This result illustrates that, at low $\mathrm{pH}$ values, the arms are very distant to each other since they are positively charged and, as $\mathrm{pH}$ increases, more closed structures are sampled. Moreover, as observed before, the sampled positions at high $\mathrm{pH}$ values are very similar to the ones in $\mathrm{ACN}$.

The described conformational analyses of the receptor suggest that the behavior in water, at low protonation, is similar to the
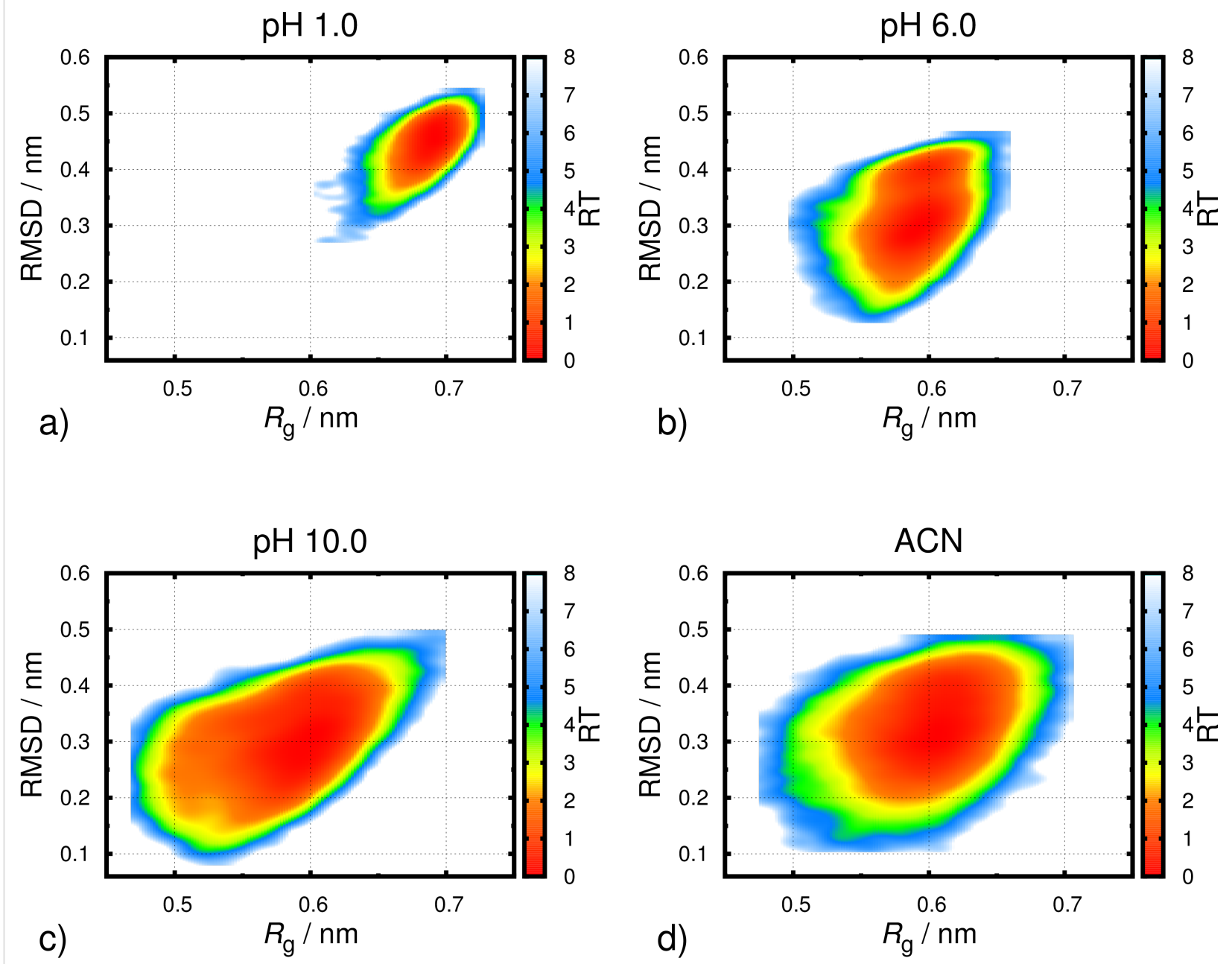

Figure 5: Free energy profiles for the receptor at pH 1.0 (a), 6.0 (b), 10.0 (c) and ACN (d) using RMSD and $R_{\mathrm{g}}$ as structural coordinates. The RMSD was calculated using the NMR derived structure as reference. 


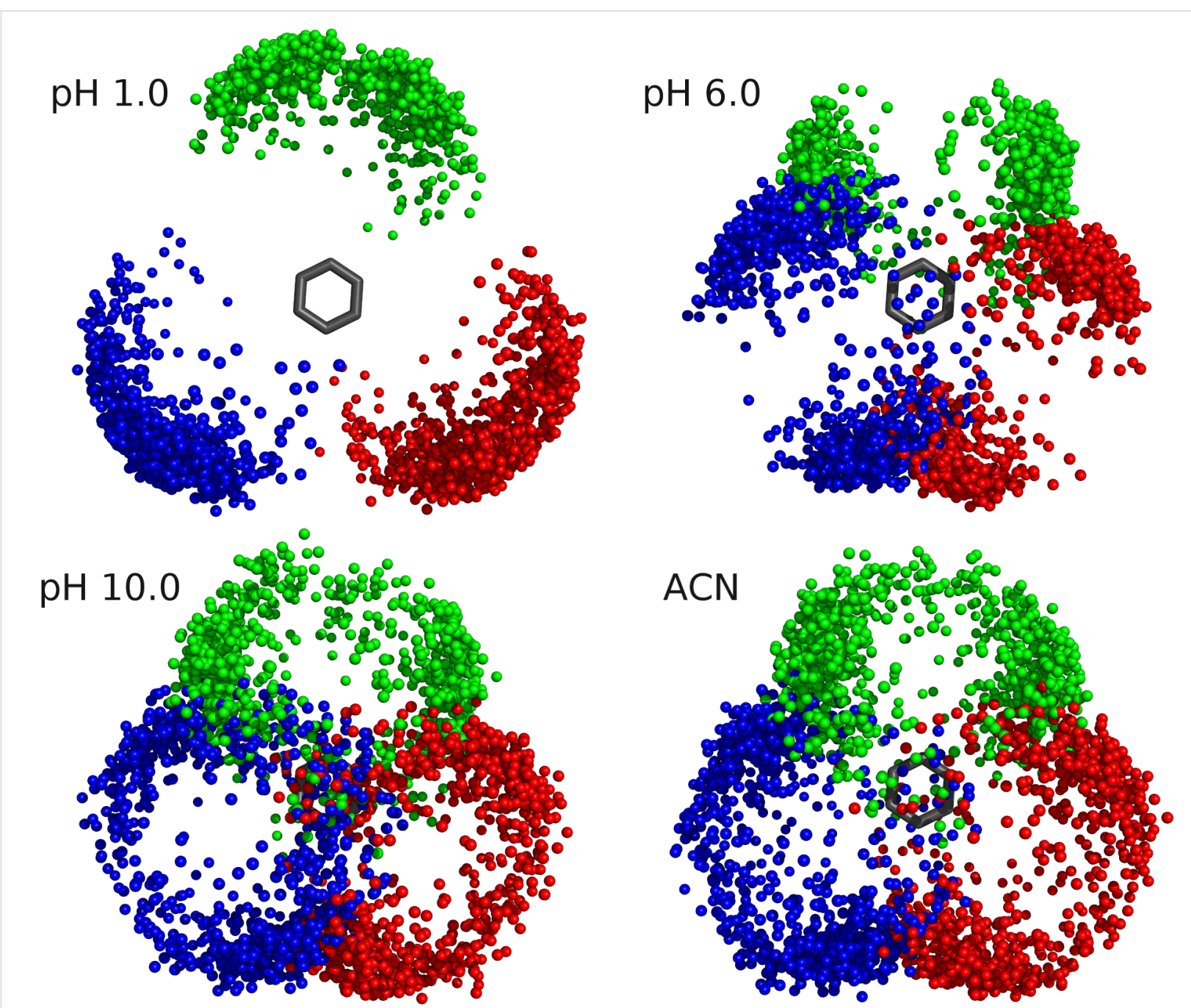

Figure 6: Schematic representation of the receptor arms positions. Pyrrolic nitrogen atoms positions relative to the phenyl ring in 900 conformations at $\mathrm{pH} 1.0,6.0,10.0$ and in $\mathrm{ACN}$.

observed in ACN. This suggests that, from a conformational point of view, the receptor would be able to bind the mannoside, both in water and ACN. However, as mentioned above, it was observed that this interaction is favorable in ACN but not in water. This may be explained by the different interactions that occur in water and ACN.

\section{Receptor/mannoside interactions}

To understand the molecular detail of the interaction between receptor and mannoside, several MM/MD simulations in water and $\mathrm{ACN}$ were performed without restraints (data not shown). In these simulations the residence time of the mannoside was very short (in the sub ns timescale). In addition, the binding event was never observed in our unrestrained simulations. Since entropy plays a crucial role in binding events they can be too slow and inaccessible in our computational timescale. Hence, to gain better insights into the molecular detail of the interaction between sugar and receptor, we performed the receptor + mannoside simulations (see Experimental section) with a position restraint between the phenyl group of the receptor and the sugar ring in the mannoside. This way, we were able to sample the interactions between the ligand and the receptor more efficiently and draw conclusions regarding the specificity of this event. In these simulations, we tested four protonation states (see Experimental section) from which $\mathrm{W}^{\mathrm{q} 3 \mathrm{a}}$ and $\mathrm{W}^{\mathrm{q} 3 \mathrm{~b}}$ refer to the slightly acidic conditions analogous to experiments [14].

The histogram of the number of hydrogen bonds in ACN and water (Figure 7) suggests that in ACN the interaction is stronger. The number of conformations with more than 1 hydrogen bond is higher in ACN. Since donors and acceptors for hydrogen bonds in the mannoside are all in the head group, this result suggests that the interaction with the receptor is more specific in ACN. In water, with increased ionization, the 
receptor samples more open conformations favoring interactions involving only one arm (1-2 hydrogen bonds) and preventing structures with more hydrogen bonds.

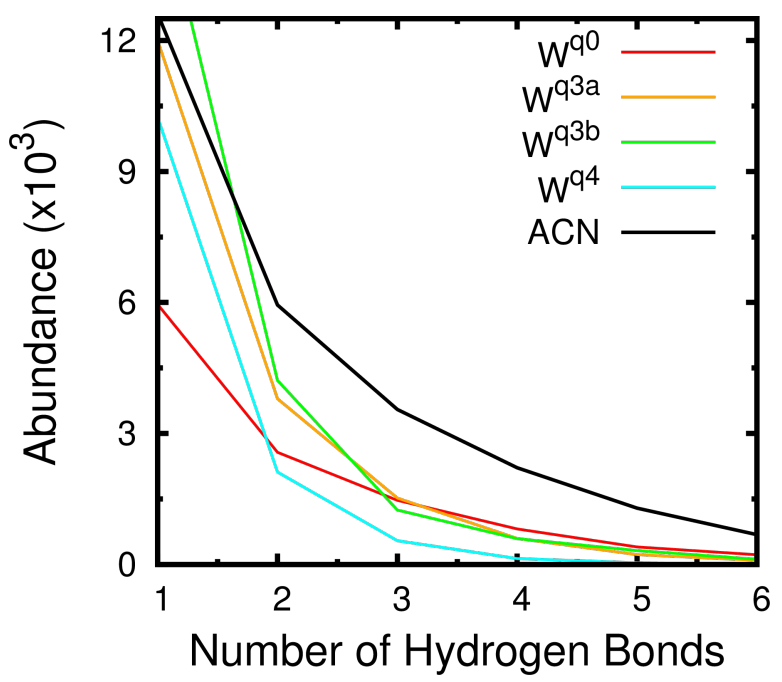

Figure 7: Histogram of the hydrogen bonds between receptor and mannoside in ACN and water (at different protonation states).

We also calculated the histogram of the distance between the center of mass of the last 4 atoms of the carbon chain of the mannoside and the 6 atoms of the phenyl ring (Figure 8). These histograms show a clear preference for lower distances in water for the fully deprotonated state $\left(\mathrm{W}^{\mathrm{q} 0}\right)$. In $\mathrm{W}^{\mathrm{q} 0}$, the interaction

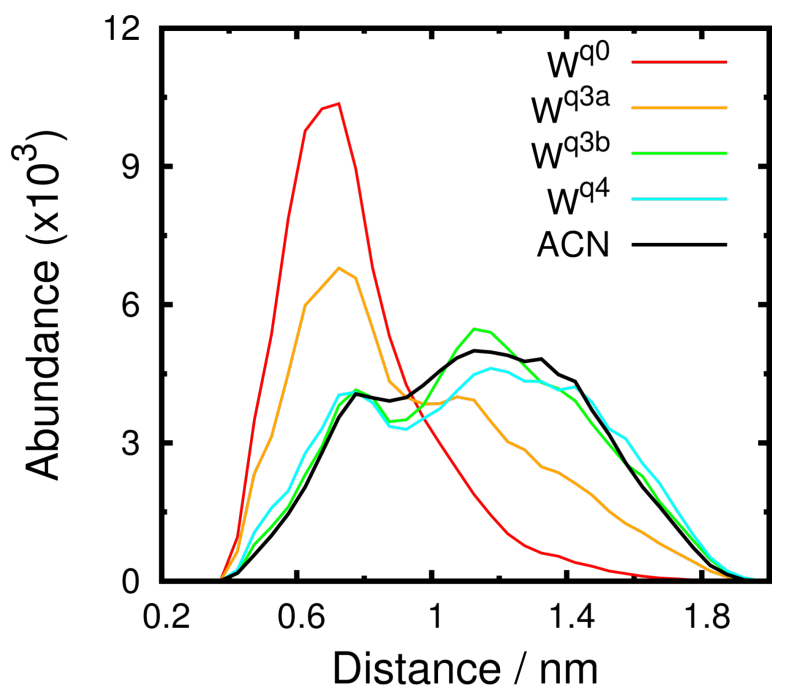

Figure 8: Distance histograms between the center of mass of the last 4 atoms of the carbon chain of the mannoside and the 6 atoms of the phenyl ring in the receptor. Calculations were done in $\mathrm{ACN}$ and water (at different protonation states). between the carbon chain and the phenyl ring is stronger and stabilized by more close conformations. The protonation of the $1^{\text {st }}$ generation amino groups $\left(\mathrm{W}^{\mathrm{q} 3 \mathrm{~b}}\right.$ and $\mathrm{W}^{\mathrm{q} 4}$ ) induces a higher solvent exposure which destabilizes the mentioned hydrophobic interaction. As a result, these systems behave like ACN where there is no significant interaction. These observations are illustrated with two typical conformations in $\mathrm{W}^{\mathrm{q} 0}$ and $\mathrm{ACN}$ (Figure 9). In $\mathrm{ACN}$, a strong interaction between the sugar ring and the arms of the receptor is observed and, in water, the carbon chain lays close to the ring stabilized by the hydrophobic effect.
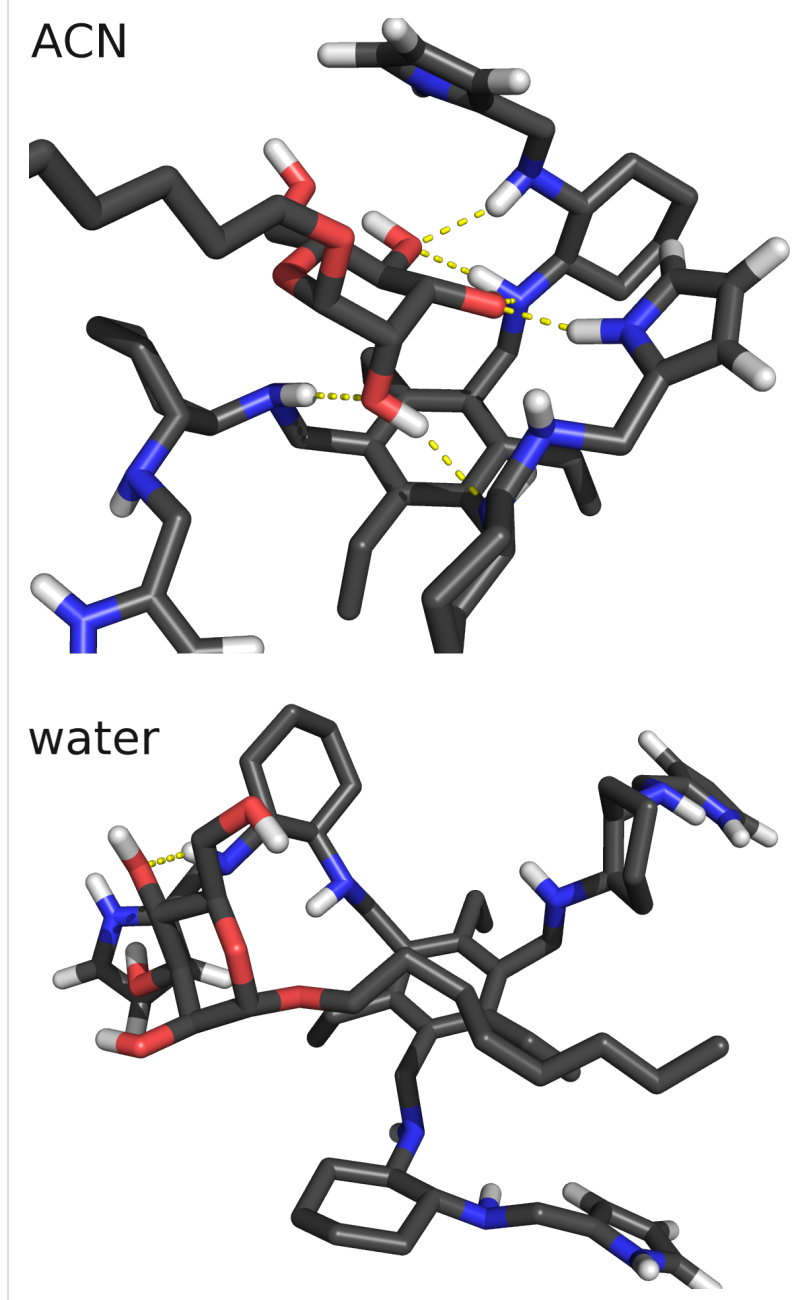

Figure 9: Typical conformations in water and ACN. The selected conformations have 6 hydrogen bonds in $\mathrm{ACN}$ and 1 in water.

Altogether, these results show that, in ACN, hydrogen bonds are stronger and, probably, the main responsible for the intermolecular interaction. In water, hydrophobic effects may play an important role, rendering the interactions between the carbon 
chain and the phenyl group a structural determinant when all $1^{\text {st }}$ generation amino groups are neutral.

\section{Conclusion}

In this work, we performed a full $\mathrm{pH}$ titration of the diaminopyrrolic tripodal receptor and a detailed analysis of the conformational dependence of this molecule with $\mathrm{pH}$. We also studied the interaction between the receptor and the mannoside. Our results show that there is no significant difference in the conformational space of the receptor in $\mathrm{ACN}$ and in water (at $\mathrm{pH}>4.0$ ). Interestingly, in the presence of the mannoside, the number of hydrogen bonds between the two molecules is significantly larger in ACN than in water. This is probably the reason that the receptor is able to be selective towards mannoside in the organic solvent. There are several works, both theoretical [38-40] and experimental [1-6,37,41,42], showing that the interaction between sugars and their receptors is mainly driven by hydrogen bonds. In fact, there are several experimental structures of mannosides similar to the one used in this work in the protein data bank that also show a significant hydrogen bond network stabilizing the interaction between the sugar molecule and the protein (PDB IDs: 4avi [41], 1tr7 [42], luwf [42]). These observations indicate that the cause hindering the receptor to be active in water lies in the incapacity to form sufficient hydrogen bonds with the mannoside. Probably, the high propensity to form hydrogen bonds with water and the high flexibility of the arms of the receptor, are the main reasons that explain its low binding affinity in aqueous solvent.

This work also presents a new application of the stochastic titration constant-pH molecular dynamics method to a synthetic receptor for sugars. This method was able to describe the proto- nation/conformation coupling by correctly sample the occupation of titrable residues at the desired $\mathrm{pH}$ value.

\section{Experimental \\ Simulations setup}

As indicated in the introduction, two sets of simulations were performed (Table 1): A set of constant-pH MD simulations at $10 \mathrm{pH}$ values (3 replicates of $100 \mathrm{~ns}$ each) and a set of MM/MD simulations in both water (at different protonation states) and acetonitrile (10 replicates of $100 \mathrm{~ns}$ each). The choice of protonation states was based on the $\mathrm{pH}$-dependent proton distribution in the receptor from the constant-pH MD simulations. The fully deprotonated state $\left(\mathrm{W}^{\mathrm{q} 0}\right)$ is typical of a high $\mathrm{pH}$ value $(\sim 10)$, the two states with 3 protons $\left(\mathrm{W}^{\mathrm{q} 3 \mathrm{a}}\right.$ and $\mathrm{W}^{\mathrm{q} 3 \mathrm{~b}}$ ) are typical of intermediate $\mathrm{pH}$ values $(\sim 4-7)$, and the 4 protons state $\left(\mathrm{W}^{\mathrm{q} 4}\right)$ is representative of $\mathrm{pH} 3.0$. This $\mathrm{pH}$ assignment to the protonation states was done according to the population analysis obtained in the constant-pH MD simulations (see Supporting Information File 1).

\section{Constant-pH MD settings}

All constant-pH MD simulations were performed using the stochastic titration constant-pH MD method implemented for the GROMACS package, developed by Baptista et al. [15,21]. These simulations ran following a stop-and-go procedure that alters between a protonation state calculation where the new states are obtained from a Monte Carlo run using Poisson-Boltzmann derived energy terms and two MM/MD runs (one with the solute frozen to allow it to adapt to the new protonation states $-0.2 \mathrm{ps}$ and another of the unconstrained system $-2.0 \mathrm{ps}$ ). All six amino groups were titrated at all simulated $\mathrm{pH}$ values.

\begin{tabular}{|c|c|c|c|c|c|}
\hline Solute & $\begin{array}{l}\text { Simulation } \\
\text { method }\end{array}$ & Solvent & Protonation state & $\mathrm{pH}$ & Replicates \\
\hline \multirow{2}{*}{ receptor } & Constant-pH MD & $\begin{array}{l}\text { Water (1268 } \\
\text { molecules) }\end{array}$ & NA & $\begin{array}{c}1,2,3,4,5,6,7,8,9 \\
\text { and } 10\end{array}$ & 3 per $\mathrm{pH}$ \\
\hline & & ACN (535 molecules) & Fully deprotonated & \multirow{6}{*}{ NA } & 3 \\
\hline \multirow{5}{*}{$\begin{array}{l}\text { receptor }+ \\
\text { mannoside }\end{array}$} & \multirow{5}{*}{ MD } & \multirow{4}{*}{$\begin{array}{l}\text { Water (1926 } \\
\text { molecules) }\end{array}$} & Fully deprotonated ( $\mathrm{W}^{\mathrm{q} 0}$ ) & & \multirow{5}{*}{10} \\
\hline & & & $\begin{array}{c}3 \text { protons in } 2^{\text {nd }} \text { generation } \\
\left(W^{93 a}\right)\end{array}$ & & \\
\hline & & & $\begin{array}{l}2 \text { protons in } 2^{\text {nd }} \text { generation and } \\
11 \text { in } 1^{\text {st }}\left(\mathrm{W}^{3} 3 \mathrm{~b}\right)\end{array}$ & & \\
\hline & & & $\begin{array}{c}3 \text { protons in } 2^{\text {nd }} \text { generation and } \\
11 \text { in } 1^{\text {st }}\left(\mathrm{W}^{94}\right)\end{array}$ & & \\
\hline & & ACN (612 molecules) & Fully deprotonated & & \\
\hline
\end{tabular}


$M M / M D$ settings (MM/MD simulations and $M M / M D$ part of constant-pH MD simulations)

The MM/MD simulations were performed using GROMACS 4.0.7 $[43,44]$ and adapted parameters from the GROMOS $56 \mathrm{~A}_{\mathrm{CARBO}}[45,46]$ force field. In all the constant protonation simulations, the neutral secondary amino groups were built in the $\mathrm{R}$ configuration. In the constant-pH MD simulations, the chirality of the amino groups is not important due to the continuous exchange of protons. A time step of $2 \mathrm{fs}$ was used in the leap-frog algorithm. A rhombic dodecahedral simulation box with periodic boundary conditions was used. The non-bonded interactions were treated using a twin-range cutoff of $0.8 / 1.4 \mathrm{~nm}$ and the neighbor lists were updated every 5 steps $(10 \mathrm{fs})$. Electrostatic long range interactions were treated with a generalized reaction field [47] with an ionic strength of $0.1 \mathrm{M}$ and a relative dielectric constant of 54 for systems with water [48] and 35.84 for systems solvated with acetonitrile [49]. The v-rescale temperature coupling was used $(298.0 \mathrm{~K})$ with a coupling constant of 0.1 with solvent and solute separately coupled to the bath. The Berendsen coupling bath [50] was used to treat pressure ( 1 bar) with coupling constant 0.5 . Isothermal compressibility of $4.50 \times 10^{-5} \mathrm{bar}^{-1}$ for water and $8.17 \times 10^{-5} \mathrm{bar}^{-1}$ for acetonitrile [51,52] were used. All bonds were constrained using the P-LINCS algorithm [53].

The energy minimization steps were performed using a combination of both steepest descent and limited-memory Broyden-Fletcher-Goldfarb-Shanno methods. The initiation was performed in 3 steps of 100 ps, 200 ps, and 200 ps with different restraints.

In the receptor + mannoside simulations, a distance restraint of $100 \mathrm{~kJ} \mathrm{~mol}^{-1} \mathrm{~nm}^{-2}$ was used between all pairs of atoms in the two rings (6 in substituted phenyl group in the receptor and 6 in the sugar ring of the mannoside). Hence, a penalty was added when the distance between any pair of atoms in the two rings exceeded $1.0 \mathrm{~nm}$. The used function for this energy penalty is quadratic between 1.0 and $1.2 \mathrm{~nm}$ and linear above $1.2 \mathrm{~nm}$. This restraint creates a sphere around the receptor that maintains the two molecules close to each other. It is important to mention that within this sphere, no unphysical restrain forces are applied to the interacting molecules.

\section{$\mathrm{PB} / \mathrm{MC}$ settings}

The $\mathrm{PB} / \mathrm{MC}$ calculations were done as previously described [26]. The MEAD 2.2.9 [25] software package was used for PB calculations performed with the atomic charges and radii taken from the MM/MD force field. The model compound $\mathrm{p} K_{\mathrm{a}}$ value used (10.64 for all equivalent amino groups) is the $\mathrm{p} K_{\mathrm{a}}$ of the dimethylamine [54]. It was used a dielectric constant of 2 for the solute and 80 for the solvent. Grid spacing of $0.1 \mathrm{~nm}$, in the coarser calculation, and $0.025 \mathrm{~nm}$, in the focusing procedure, were used in the finite difference method [55]. The molecular surface was determined using a rolling probe of $0.14 \mathrm{~nm}$ and the Stern layer was $0.2 \mathrm{~nm}$. The temperature used was $298 \mathrm{~K}$ and the ionic strength was $0.1 \mathrm{M}$.

The MC calculations were performed using the PETIT (version 1.5) [56] software with $10^{5}$ steps for each calculation. Each step consisted of a cycle of random choices of protonation state (including tautomeric forms) for all individual sites and for pairs of sites with a coupling above $2.0 \mathrm{p} K_{\mathrm{a}}$ units [56,57], followed by the acceptance/rejection step according to Metropolis criterion [58]. The last protonation state is then used for the MM/MD part.

\section{Analyses}

The last $90 \mathrm{~ns}$ of each simulation were used for analyses. Several tools from the GROMACS software package $[43,44]$ were used and others were developed in-house. The RMSD calculations followed a previously published procedure [59] that takes into account the symmetry of the receptor. The PyMOL 0.99RC6 software (http://www.pymol.org) was used to obtain rendered conformational images.

Energy landscapes were obtained from different 2D spaces by computing kernel estimates of the data probability densities [60] on grids of $2 \mathrm{pm}^{2}$ bins, using a Gaussian kernel. The probability density surface was then converted to an energy surface according to:

$$
E(\vec{x})=-R T \ln \frac{P(\vec{x})}{P_{\max }}
$$

where $\vec{x}$ is a coordinate in a $2 \mathrm{D}$ space and $P_{\max }$ is the maximum of the probability density function, $P(\vec{x})$.

The calculations of correlation-corrected errors for averages were computed using standard methods based on the auto-correlation function of the property measured to determine the number of independent blocks in the simulations [61].

\section{Supporting Information}

\section{Supporting Information File 1}

Diagrams with the population of each microstate, histograms of $R_{\mathrm{g}}$, free energy profiles and schematic representation of the position of the arms at all $\mathrm{pH}$ values. [http://www.beilstein-journals.org/bjoc/content/ supplementary/1860-5397-10-156-S1.pdf] 


\section{Acknowledgments}

The authors thank Cristina Nativi and Stefano Roelens for the NMR derived structure and useful discussions. We also thank António M. Baptista for several fruitful discussions and Rafael Nunes for the careful reading of the manuscript. Finally, we thank Sara R. R. Campos and Luís C. S. Filipe for several tools used to obtain the energy landscapes. We acknowledge financial support from Fundação para a Ciência e Tecnologia, through project PEst-OE/QUI/UI0612/2013 and grant SFRH/ $\mathrm{BD} / 81017 / 2011$, and COST program through action CMST/ COST-Action/CM1102.

\section{References}

1. Davis, A. P.; Wareham, R. S. Angew. Chem., Int. Ed. 1999, 38, 2978. doi:10.1002/(SICI)1521-3773(19991018)38:20<2978::AID-ANIE2978>3 0.CO;2-P

2. Davis, A. P. Org. Biomol. Chem. 2009, 7, 3629. doi:10.1039/b909856a

3. Jin, S.; Cheng, Y.; Reid, S.; Li, M.; Wang, B. Med. Res. Rev. 2010, 30, 171. doi:10.1002/med.20155

4. Mazik, M. Chem. Soc. Rev. 2009, 38, 935. doi:10.1039/b710910p

5. Nakagawa, Y.; Ito, Y. Trends Glycosci. Glycotechnol. 2012, 24, 1. doi:10.4052/tigg.24.1

6. Walker, D. B.; Joshi, G.; Davis, A. P. Cell. Mol. Life Sci. 2009, 66, 3177. doi:10.1007/s00018-009-0081-8

7. Collins, P. M.; Ferrier, R. J. Monosaccharides: their chemistry and their roles in natural products; Wiley \& Sons: Chichester, New York, 1995.

8. Lehninger, A. L.; Nelson, D. L.; Cox, M. M. Lehninger principles of biochemistry, 4th ed.; W. H. Freeman: New York, 2005.

9. Dwek, R. A. Chem. Rev. 1996, 96, 683. doi:10.1021/cr940283b

10. Varki, A. Glycobiology 1993, 3, 97. doi:10.1093/glycob/3.2.97

11. Ardá, A.; Cañada, F. J.; Nativi, C.; Francesconi, O.; Gabrielli, G.; lenco, A.; Jiménez-Barbero, J.; Roelens, S. Chem.-Eur. J. 2011, 17, 4821. doi:10.1002/chem.201002872

12. Nativi, C.; Cacciarini, M.; Francesconi, O.; Moneti, G.; Roelens, S. Org. Lett. 2007, 9, 4685. doi:10.1021/ol701959r

13. Nativi, C.; Francesconi, O.; Gabrielli, G.; Vacca, A.; Roelens, S. Chem.-Eur. J. 2011, 17, 4814. doi:10.1002/chem.201002871

14. Nativi, C.; Francesconi, O.; Roelens, S. Personal communication regarding the inability of the receptor to bind the mannoside in water.

15. Baptista, A. M.; Teixeira, V. H.; Soares, C. M. J. Chem. Phys. 2002, 117, 4184. doi:10.1063/1.1497164

16. Börjesson, U.; Hünenberger, P. H. J. Chem. Phys. 2001, 114, 9706. doi:10.1063/1.1370959

17. Bürgi, R.; Kollman, P. A.; van Gunsteren, W. F. Proteins: Struct., Funct., Bioinf. 2002, 47, 469. doi:10.1002/prot.10046

18. Dlugosz, M.; Antosiewicz, J. M. Chem. Phys. 2004, 302, 161. doi:10.1016/j.chemphys.2004.03.031

19. Dlugosz, M.; Antosiewicz, J. M.; Robertson, A. D. Phys. Rev. E 2004, 69, 021915. doi:10.1103/PhysRevE.69.021915

20. Lee, M. S.; Salsbury, F. R., Jr.; Brooks, C. L., III. Proteins: Struct., Funct., Bioinf. 2004, 56, 738. doi:10.1002/prot.20128

21. Machuqueiro, M.; Baptista, A. M. J. Phys. Chem. B 2006, 110, 2927. doi:10.1021/jp056456q

22. Mongan, J.; Case, D. A.; McCammon, J. A. J. Comput. Chem. 2004, 25, 2038. doi:10.1002/jcc.20139

23. Stern, H. A. J. Chem. Phys. 2007, 126, 164112. doi:10.1063/1.2731781
24. Vorobjev, Y. N. J. Comput. Chem. 2012, 33, 832. doi:10.1002/jcc.22909

25. Bashford, D.; Gerwert, K. J. Mol. Biol. 1992, 224, 473. doi:10.1016/0022-2836(92)91009-E

26. Teixeira, V. H.; Cunha, C. A.; Machuqueiro, M.; Oliveira, A. S. F.; Victor, B. L.; Soares, C. M.; Baptista, A. M. J. Phys. Chem. B 2005, 109, 14691. doi:10.1021/jp052259f

27. Campos, S. R. R.; Baptista, A. M. J. Phys. Chem. B 2009, 113, 15989. doi:10.1021/jp902991u

28. Campos, S. R. R.; Machuqueiro, M.; Baptista, A. M. J. Phys. Chem. B 2010, 114, 12692. doi:10.1021/jp104753t

29. Carvalheda, C. A.; Campos, S. R. R.; Machuqueiro, M.; Baptista, A. M. J. Chem. Inf. Model. 2013, 53, 2979. doi:10.1021/ci400479c

30. Henriques, J.; Costa, P. J.; Calhorda, M. J.; Machuqueiro, M. J. Phys. Chem. B 2013, 117, 70. doi:10.1021/jp3082134

31. Machuqueiro, M.; Baptista, A. M. Biophys. J. 2007, 92, 1836. doi:10.1529/biophysj.106.092445

32. Machuqueiro, M.; Baptista, A. M. Proteins: Struct., Funct., Bioinf. 2008, 72, 289. doi:10.1002/prot.21923

33. Machuqueiro, M.; Baptista, A. M. J. Am. Chem. Soc. 2009, 131, 12586. doi:10.1021/ja808463e

34. Machuqueiro, M.; Baptista, A. M. Proteins: Struct., Funct., Bioinf. 2011, 79, 3437. doi:10.1002/prot.23115

35. Vila-Viçosa, D.; Campos, S. R. R.; Baptista, A. M.; Machuqueiro, M. J. Phys. Chem. B 2012, 116, 8812. doi:10.1021/jp3034837

36. Vila-Viçosa, D.; Teixeira, V. H.; Santos, H. A. F.; Machuqueiro, M. J. Phys. Chem. B 2013, 117, 7507. doi:10.1021/jp401066v

37. Nakagawa, Y.; Doi, T.; Masuda, Y.; Takegoshi, K.; Igarashi, Y.; Ito, Y. J. Am. Chem. Soc. 2011, 133, 17485. doi:10.1021/ja207816h

38. Aqvist, J.; Mowbray, S. L. J. Biol. Chem. 1995, $270,9978$.

39. Lerbret, A.; Affouard, F.; Hédoux, A.; Krenzlin, S.; Siepmann, J.; Bellissent-Funel, M.-C.; Descamps, M. J. Phys. Chem. B 2012, 116, 11103. doi:10.1021/jp3058096

40. Lerbret, A.; Bordat, P.; Affouard, F.; Hédoux, A.; Guinet, Y.; Descamps, M. J. Phys. Chem. B 2007, 111, 9410 doi:10.1021/jp071946z

41. Wellens, A.; Lahmann, M.; Touaibia, M.; Vaucher, J.; Oscarson, S.; Roy, R.; Remaut, H.; Bouckaert, J. Biochemistry 2012, 51, 4790. doi:10.1021/bi300251r

42. Bouckaert, J.; Berglund, J.; Schembri, M.; De Genst, E.; Cools, L.; Wuhrer, M.; Hung, C.-S.; Pinkner, J.; Slättegård, R.; Zavialov, A.; Choudhury, D.; Langermann, S.; Hultgren, S. J.; Wyns, L.; Klemm, P.; Oscarson, S.; Knight, S. D.; De Greve, H. Mol. Microbiol. 2005, 55, 441. doi:10.1111/j.1365-2958.2004.04415.x

43. Berendsen, H. J. C.; van der Spoel, D.; van Drunen, R. Comput. Phys. Commun. 1995, 91, 43. doi:10.1016/0010-4655(95)00042-E

44. Hess, B.; Kutzner, C.; van der Spoel, D.; Lindahl, E. J. Chem. Theory Comput. 2008, 4, 435. doi:10.1021/ct700301q

45. Hansen, H. S.; Hünenberger, P. H. J. Comput. Chem. 2011, 32, 998. doi:10.1002/jcc. 21675

46. Schmid, N.; Eichenberger, A. P.; Choutko, A.; Riniker, S.; Winger, M.; Mark, A. E.; van Gunsteren, W. F. Eur. Biophys. J. 2011, 40, 843. doi:10.1007/s00249-011-0700-9

47. Tironi, I. G.; Sperb, R.; Smith, P. E.; van Gunsteren, W. F. J. Chem. Phys. 1995, 102, 5451. doi:10.1063/1.469273

48. Smith, P. E.; van Gunsteren, W. F. J. Chem. Phys. 1994, 100, 3169. doi:10.1063/1.466407

49. Barthel, J.; Kleebauer, M.; Buchner, R. J. Solution Chem. 1995, 24, 1. doi:10.1007/BF00973045 
50. Berendsen, H. J. C.; Postma, J. P. M.; van Gunsteren, W. F.; DiNola, A.; Haak, J. R. J. Chem. Phys. 1984, 81, 3684. doi:10.1063/1.448118

51. Dharmaraju, G.; Narayanaswamy, G.; Raman, G. K.

J. Chem. Eng. Data 1982, 27, 193. doi:10.1021/je00028a028

52. Narayanaswamy, G.; Dharmaraju, G.; Raman, G. K.

J. Chem. Thermodyn. 1981, 13, 327. doi:10.1016/0021-9614(81)90022-7

53. Hess, B. J. Chem. Theory Comput. 2008, 4, 116. doi:10.1021/ct700200b

54. Hall, H. K., Jr. J. Am. Chem. Soc. 1957, 79, 5441. doi:10.1021/ja01577a030

55. Gilson, M. K.; Sharp, K. A.; Honig, B. H. J. Comput. Chem. 1988, 9, 327. doi:10.1002/jcc.540090407

56. Baptista, A. M.; Soares, C. M. J. Phys. Chem. B 2001, 105, 293. doi:10.1021/jp002763e

57. Baptista, A. M.; Martel, P. J.; Soares, C. M. Biophys. J. 1999, 76, 2978. doi:10.1016/S0006-3495(99)77452-7

58. Metropolis, N.; Rosenbluth, A. W.; Rosenbluth, M. N.; Teller, A. H.; Teller, E. J. Chem. Phys. 1953, 21, 1087. doi:10.1063/1.1699114

59. Filipe, L. C. S.; Machuqueiro, M.; Baptista, A. M. J. Am. Chem. Soc. 2011, 133, 5042. doi:10.1021/ja111001v

60. Silverman, B. W. Density estimation for statistics and data analysis; Chapman and Hall: London, New York, 1986.

61. Allen, M. P.; Tildesley, D. J. Computer simulation of liquids; Clarendon Press: Oxford, England, 1987.

\section{License and Terms}

This is an Open Access article under the terms of the Creative Commons Attribution License

(http://creativecommons.org/licenses/by/2.0), which permits unrestricted use, distribution, and reproduction in any medium, provided the original work is properly cited.

The license is subject to the Beilstein Journal of Organic Chemistry terms and conditions:

(http://www.beilstein-journals.org/bjoc)

The definitive version of this article is the electronic one which can be found at:

$\underline{\text { doi: } 10.3762 / \text { bjoc. } 10.156}$ 